\title{
An Open Tubular CEC Column of Excellent Separation Efficiency for Proteomic Analysis
}

\author{
Won Jo Cheong, ${ }^{*}$ Shabi Abbas Zaidi, ${ }^{a}$ and Yune Sung Kim \\ Department of Chemistry, Inha University, Incheon 402-751, Korea. *E-mail: wjcheong@inha.ac.kr \\ Received May 25, 2014, Accepted June 18, 2014
}

Key Words : CEC capillary column, Open tubular, Molecular imprinted polymer, Tryptic digest, High separation efficiency

Proteomics aims to understand complex biological systems by analyzing protein expression, protein function, protein modifications and protein interactions. ${ }^{1}$ The conventional proteomic approach is to carry out the sequential processes of physical separation by cells or microorganisms, enrichment purification such as solid phase extraction, 2-dimensional polyamide gel electrophoresis (2-D PAGE) to result in separation of point groups, and MALDI-TOF or LC-MS-MS analyses of individual point groups. ${ }^{2-5}$ Two modes of proteome analysis have been used: top-down and bottom-up (shot-gun). In top-down proteomics, intact proteins or large protein fragments are subjected to MS analysis. ${ }^{6-8}$ In bottomup proteomics, the protein mixture is digested and the peptides generated are separated by liquid chromatography and sequenced by tandem mass spectrometry. ${ }^{1,9,10}$

Sample preparation and fractionation have also been known to be very important in proteomics. ${ }^{11} \mathrm{LC}$ has played a critical role in proteomic analyses since it has been used as a powerful tool not only in sample preparation and fractionation in top-down proteome but also in separation of digested peptides in bottom-up proteome. ${ }^{1,11-13}$ LC pre-separation and 2-D LC pre-separation can be incorporated in either on-line or off-line mode for both intact proteins and digested peptides before coupling to mass spectrometry.

A pre-separated fraction still may have many proteins or peptides owing to the complexity of proteome samples. 2-D LC has been developed and employed to resolve the sample complexity ${ }^{14-16}$ at the expense of sophistication of instruments and some reduction of reproducibility. Achievement of better separation efficiency of LC has been the continuing demand in proteomics. The typical micro- or nano- LC column packed with ca $3 \mu \mathrm{m} \mathrm{C18}$ particles shows generally good separation performance, but the practical column length has been less than $20 \mathrm{~cm}$ owing to high column back pressure, thus its overall column separation efficiency has been limited. Monolithic columns may be adopted instead, ${ }^{17,18}$ but the overall column separation efficiency has been limited, too.

One way to enhance column separation efficiency is to increase the column length. However, the column back pressure is also increased, thus adoption of the open tubular

${ }^{a}$ Current address: Department of Chemistry, Kwangwoon Unversity, Seoul 139-701, Korea column format may be useful. Such LC column format has been actually developed and employed in proteomic analysis mostly coupled to mass spectrometry in gradient elution mode. ${ }^{19-24}$ Long and narrow silica capillaries of $c a 10 \mu \mathrm{m}$ I.D. and 3-5 m length have been modified to have a thin ( $c a$ 1-2 $\mu \mathrm{m}$ ) porous layer open tubular (PLOT) polymer film on the inner surface of capillary, and the resultant columns showed superb peak separation capacity. ${ }^{19-24}$ Such narrow I.D. was required in LC application to minimize band broadening. The feasibility of such columns in practical routine analysis is questionable since clogging of column may be easily occurred in the procedure of preparation and operation.

CEC may be used instead of LC to overcome the above problem owing to the uniform velocity distribution across the capillary diameter. ${ }^{25,26}$ An open tubular column of much wider I.D. (ca $50 \mu \mathrm{m})$ and much shorter length $($ ca $50 \mathrm{~cm})$ can be used to achieve good separation without column clogging problem. Use of CEC for proteomic analysis has kept on increasing as introduced in some review articles. ${ }^{27-31}$ CEC-MS also has been increasingly employed for its outstanding performance in spite of the technical difficulties in constructing the system. ${ }^{31} \mathrm{CEC}$ can be employed in the 2-D separation systems, too. ${ }^{16}$ In most of the above CEC applications in proteomics, however, either packed or monolithic columns have been used, and nano-particle based pseudostationary phases have been sometimes used. ${ }^{30}$

The best level of column separation efficiency in proteomic analysis has been obtained by open tubular CEC $(\text { OT-CEC) })^{32-34}$ although the OT-CEC approach has not been widespread in this research area probably due to the sophisticated preparation protocol of OT stationary phases.

In our laboratory, OT-CEC columns have been prepared by making use of molecularly imprinted polymer (MIP) to show the highest level of column separation efficiency for chiral separation. ${ }^{35-38}$ Molecular imprinted polymer (MIP) is prepared with a reaction mixture composed of a template, a functional monomer (or two), a cross-linking monomer (or two), a polymerization initiator in a porogenic solvent. ${ }^{39}$ After completion of polymerization, a three-dimensional polymer network is formed where the template molecules are trapped. The template molecules are eliminated by thorough washing. The MIP approach was used to generate cavities complementary to the template in size, shape, and 
molecular interactions.

We suspect that the MIP technique may be used in preparation of OT columns for proteomic analysis where the template is used for formation of pores. Thus an easy template of proper molecular weight may be used for such purpose. In this study, an OT-CEC column has been developed for especially bottom-up proteomic analysis. Polyethylene glycol with average molecular weight of 10,000 was found as the useful template.

We initially tried to make a useful OT-CEC column for separation of proteins. A test mix composed of lysozyme, ribonuclease $\mathrm{A}$, cytochrome- $\mathrm{C}, \alpha$-chymotrypsinogen $\mathrm{A}$, and myoglobin, was prepared to examine the separation performance of the column. The formulation of reaction mixture was obtained from the one that was used for preparation of the successful MIP OT-CEC columns ${ }^{35-38}$ with some modifications. The general formulation had been as follows: template molecule $(0.020 \mathrm{mmol})$, methacylic acid $(8.2 \mu \mathrm{L})$, EDMA $(59 \mu \mathrm{L})$, 4-styrenesulfonic acid (2 mg) and AIBN $(3.5 \mathrm{mg})$ dissolved in $1 \mathrm{~mL} \mathrm{9/1} \mathrm{(v/v)} \mathrm{acetonitrile}(\mathrm{ACN}) / 2-$ propanol. Polyethylene glycol was chosen as the template of this study since it is easily available polymer compound compatible with the solvent system of the reaction mixture. The functional monomer chosen for this study was 4-aminostyrene instead of the combination of methacrylic acid and 4-styrenesulfonic acid since amino functional groups are more useful than acidic functional groups for retention of basic proteins. The other components and compositions were maintained the same.

The reaction mixture was composed of PEG (MW 10,000) $4.9 \mathrm{mg}$, 4-aminostyrene $8.2 \mu \mathrm{L}$, EDMA $59 \mu \mathrm{L}$, AIBN 3.5 $\mathrm{mg}$ dissolved in $1.0 \mathrm{~mL} 9 / 1(\mathrm{v} / \mathrm{v}) \mathrm{ACN} / 2$-propanol. The molecular weight of PEG was a very critical factor for the separation performance of the resultant OT-CEC column. It seems that there is a certain range of PEG molecular weight for obtaining useful OT-CEC columns as shown in Figure 1. The reason is not clear at present, and we only guess that it is related to formation pores of proper size. Characterization of the fabricated OT phase is difficult since it is of very small amount and it is not easily removable from the column without physical or chemical damage. It should also be noted that only the phase prepared in the OT format showed the good results. The bulk phase prepared in a vial with the same formulation showed very poor chromatographic performance.

The resultant OT-CEC column prepared with PEG 10,000 showed quite good separation of the protein test mix (Fig. 1) although it is not satisfactory. However, very good results were observed for separation of peptides (tryptic digest).

The formulation of the reaction mixture was further optimized to obtain better separation performance of the resultant phase for the tryptic digest of cytochrome $\mathrm{C}$. The optimum molecular weight of PEG was again found 10,000. However, the amount of PEG was increased twice. Additional increase of PEG was abandoned for the solubility limit. The amount of functional monomer (4-aminostyrene) was also varied, and three-fold increase was found the

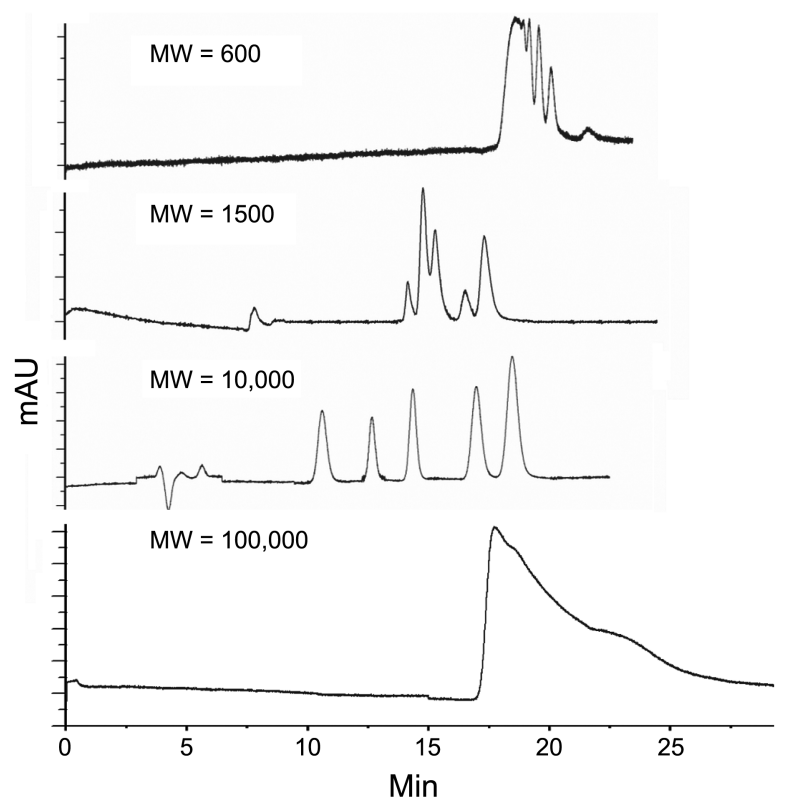

Figure 1. The effect of molecular weight of polyethylene glycol on the separation performance of the resultant OT-CEC column. Eluent: $60 / 40(\mathrm{v} / \mathrm{v}) \mathrm{ACN} / 50 \mathrm{mM}$ phosphate buffer of $\mathrm{pH} 6.0$, Injection: $5 \mathrm{mbar} / 4 \mathrm{~s}$, Applied potential: $-20 \mathrm{KV}$, Temperature: 25 ${ }^{\circ} \mathrm{C}$, wavelength: $214 \mathrm{~nm}$. Elution order: lysozyme, ribonuclease A, cytochrome-C, $\alpha$-chymotrypsinogen A, myoglobin.

optimum content. Too high content of 4-aminostyrene in the reaction mixture caused clogging of the capillary column. Thus the optimum formulation was PEG (MW 10,000) 9.8 mg, 4-aminostyrene $24.6 \mu \mathrm{L}$, EDMA $59 \mu \mathrm{L}$, AIBN $3.5 \mathrm{mg}$ dissolved in $1.0 \mathrm{~mL} 9 / 1$ (v/v) ACN/2-propanol.

The resultant OT-CEC capillary column showed superb separation efficiency for peptides of the digested cytochrome C (Fig. 2). The CEC elution conditions were also optimized.

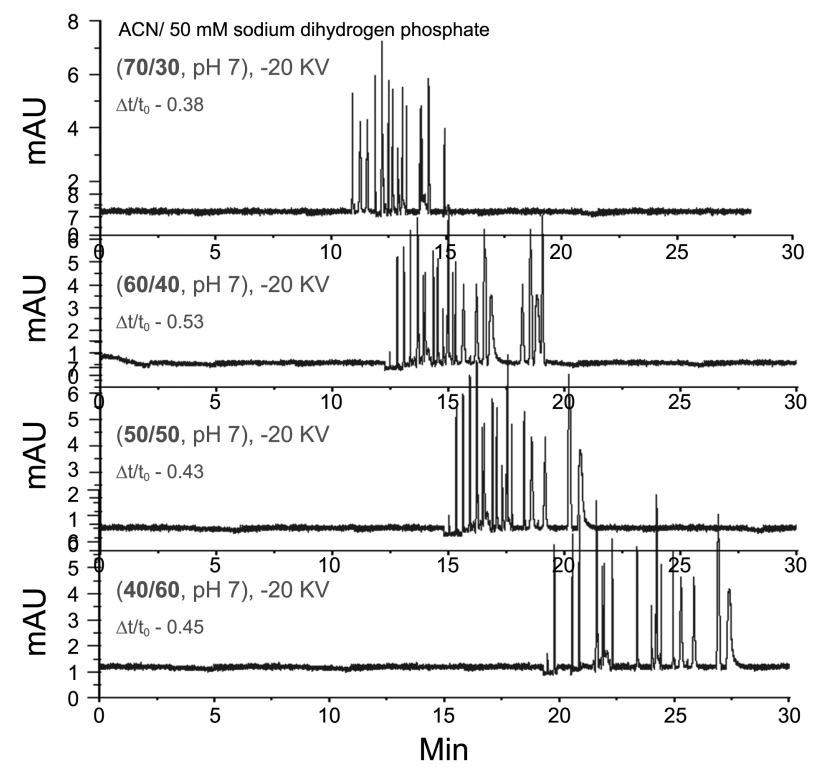

Figure 2. The effect of eluent composition on the separation performance of the OT-CEC column for the tryptic digest of cytochrome C. Eluent: ACN/50 mM phosphate buffer of $\mathrm{pH} 7.0$. The other conditions are the same as in Figure 1. 


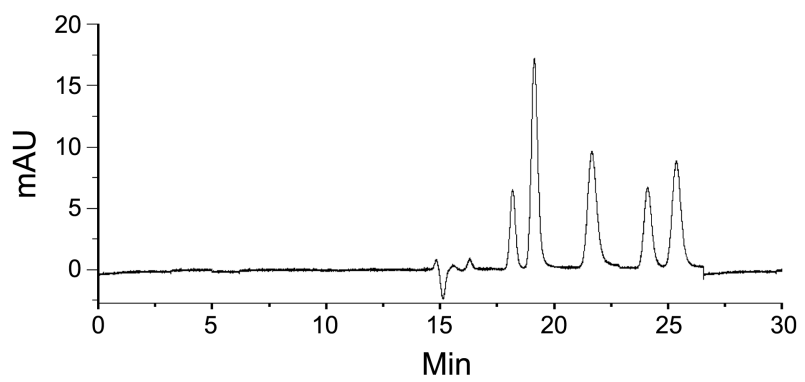

Figure 3. The electrophoregram of the protein sample obtained with the OT-CEC column developed for optimized separation of the tryptic digest. The other conditions are the same as in Figure 2. Eluent: 60/40 (v/v) ACN/50 mM phosphate buffer of $\mathrm{pH} 7.0$. Elution order: lysozyme, ribonuclease A, cytochrome-C, $\alpha$ chymotrypsinogen A, myoglobin.

The optimum $\mathrm{pH}$ was found 7.0. A unique parameter $\left(\Delta \mathrm{t} / \mathrm{t}_{\mathrm{o}}\right)$ was defined as a measure of separation performance where $\Delta t$ is the retention time range for the peptides and $t_{0}$ is the retention time of EOF (electro-osmotic flow) marker (acetone). As shown in Figure 2, 60/40 (v/v) ACN/50 mM phosphate buffer was found the eluent to result in the highest $\Delta \mathrm{t} / \mathrm{t}_{\mathrm{t}}$. The maximum number of observed peaks (20) was obtained with that eluent, too.

The numbers of theoretical plates $(\mathrm{N})$ of peptide peaks under the optimized elution conditions were at least better than $200,000 / \mathrm{m}$ and mostly better than $500,000 / \mathrm{m}$ (Fig. 2). For some peaks, the $\mathrm{N}$ values were better than $1,000,000 / \mathrm{m}$. Despite the excellent separation efficiency, the peak capacity of this study was not so great owing to the rather low $\Delta \mathrm{t} / \mathrm{t}_{\mathrm{t}}$. It should be noted that the isocratic elution mode has been used in this study since CEC is hardly compatible with gradient elution. Future realization of gradient CEC would enable dramatic improvement in separation capacity.

The above column developed for optimized separation of peptides was, in turn, applied to separation of proteins (Fig. 3 ) and the separation efficiency was improved much better than that of Figure 1. The $\mathrm{N}$ values of proteins were better than $70,000 / \mathrm{m}$.

The repeatability of preparation of the OT-CEC column was examined for 3 batches of columns, and the relative standard deviations in retention times and $\mathrm{N}$ were better than $4.0 \%$. The day-to-day reproducibility for a single column was better than $2.2 \%$, and the reproducibility for a series of sequential runs within a day was better than $1.4 \%$.

Thus the OT-CEC capillary column of this study has proved to be useful especially for bottom-up proteomic analysis (separation of peptides), and also usable for separation of proteins. Further study will be focused on enhancement of $\Delta t / t_{0}$ to have a better peak capacity, and such study is underway.

\section{Experimental}

Materials. Glacial acetic acid, trifluoroacetic acid (TFA), polyethylene glycol (PEG), sodium hydrogen phosphate, sodium dihydrogen phosphate, azobisisobutyronitrile (AIBN), 4-aminostyrene, ethyleneglycol dimetnacryalte (EDMA), $\gamma$ methacryloxypropyl trimethoxysilane (MAPS), lysozyme, ribonuclease A, $\alpha$-chymotrypsinogen A, myoglobin, cytochrome C, and trypsin were purchased from Sigma-Aldrich (St. Louis, MO, USA). HPLC grade methanol, acetonitrile (ACN), 2-propanol, acetone, and water were obtained from Mallinckrodt Baker (Phillipsburg, NJ, USA). Silica capillaries (50 mm ID, $365 \mathrm{~mm}$ OD) were purchased from Grace (Deerfield, IL, USA).

Instrument. CEC experiments were performed on an Agilent (Waldbronn, Germany) $\mathrm{HP}^{3 \mathrm{D}} \mathrm{CE}$ system with a diode array detector and the Chemstation data processing software. The stock buffer solution (50 $\mathrm{mM}$ phosphate) was prepared in distilled water and kept in a refrigerator. Later, the $\mathrm{pH}$ of phosphate buffer was controlled to the desired $\mathrm{pH}$ followed by acetonitrile addition to get the final mobile phase. All the samples and eluents were filtered through a $0.2 \mu \mathrm{m}$ cellulose membrane before analysis. Samples were injected hydrodynamically for $4 \mathrm{~s}$ under a pressure of $5 \mathrm{mbar}$. The detection wavelength was set to $214 \mathrm{~nm}$. All the separations were carried out at a constant $\mathrm{CE}$ voltage of $-20 \mathrm{kV}$ and a temperature of $25{ }^{\circ} \mathrm{C}$ throughout. The OT-MIP column was flushed by running the eluent for about $1 \mathrm{~h}$ to acquire the stable baseline.

Tryptic Digest and Protein Samples. Cytochrome C 2.5 mg was mixed with trypsin $1.0 \mathrm{mg}, 2.0 \mathrm{M}$ urea $500 \mathrm{uL}, 0.1$ $\mathrm{M}$ ammonium bicarbonate $500 \mathrm{uL}$, and incubated for $24 \mathrm{~h}$ at $37^{\circ} \mathrm{C}$. Then it was quenched with $1 \mathrm{~mL} 0.1 \%$ TFA and stored in a freezer until analysis. The protein sample was prepared by dissolving $1.0 \mathrm{mg}$ each of lysozyme, ribonuclease $\mathrm{A}, \alpha$-chymotrypsinogen $\mathrm{A}$, myoglobin, cytochrome $\mathrm{C}$ in $1.0 \mathrm{~mL}$ water, and stored in a freezer. Later, it was diluted 1,000 times in the mobile phase and injected.

Preparation of OT-CEC Column. The fused silica capillary was modified according to the procedure published elsewhere ${ }^{35-38}$ Briefly, the silica capillary of $50 \mathrm{~cm}$ length was treated with $1 \mathrm{M} \mathrm{NaOH}$, washed with water, $0.1 \mathrm{M} \mathrm{HCl}$, water, and acetone in sequence, and dried under a flow of $\mathrm{N}_{2}$. A solution composed of $4 \mu \mathrm{L}$ MAPS in $1.0 \mathrm{~mL}$ of 6.0 $\mathrm{mM}$ acetic acid was filled in the capillary for $6 \mathrm{~h}$ and the capillary was flushed thoroughly with methanol and dried under a nitrogen flow. After some trial-and-error based optimization, a mixture was prepared for formation of OT stationary phase for separation of proteins as follows: PEG (MW 10,000) 4.9 mg, 4-aminostyrene $8.2 \mu \mathrm{L}$, EDMA 59 $\mu \mathrm{L}$, AIBN $3.5 \mathrm{mg}$ dissolved in $1.0 \mathrm{~mL}$ 9/1 (v/v) ACN/2-propanol. The mixture was sonicated for $10 \mathrm{~min}$ and purged with nitrogen for $10 \mathrm{~min}$. A piece of silica capillary was filled with the mixture and both capillary ends were sealed with rubber plugs. The reaction was carried out for $4 \mathrm{~h}$ at 50 ${ }^{\circ} \mathrm{C}$, then the capillary was thoroughly flushed with ACN, 9/1 $(\mathrm{v} / \mathrm{v})$ methanol/acetic acid, 5/5 (v/v) methanol/water in sequence. The same procedure was repeated for preparation of OT-CEC columns for the tryptic digest (separation of peptides) with somewhat different formulation of reaction mixture. The optimum formulation was found as follows: PEG (MW 10,000) 9.8 mg, 4-aminostyrene 24.6 $\mu \mathrm{L}$, EDMA 
$59 \mu \mathrm{L}$, AIBN $3.5 \mathrm{mg}$ dissolved in $1.0 \mathrm{~mL}$ 9/1 (v/v) ACN/2propanol.

Optimization of Separation of Tryptic Digest. In addition to the optimization of formulation of reaction mixture, the elution conditions were also optimized by varying $\mathrm{pH}$ and mobile phase composition.

Acknowledgments. This research was supported by Basic Science Research Program through the National Research Foundation of Korea (NRF) funded by the Ministry of Science, ICT \& Future Planning (2013R1A2A2A01067201).

\section{References}

1. Ye, M.; Jiang, X.; Feng, S.; Tian, R.; Zou, H. Trends Anal. Chem. 2007, 26, 80-84.

2. Govorun, V. M.; Archakov, A. I. Biochemistry (Moscow) 2002, 67, 1109-1123.

3. Shi1, Y.; Xiang, R.; Horváth, C.; Wilkins, J. A. J. Chromatogr. A 2004, 1053, 27-36.

4. Kubota, K.; Kosaka, T.; Ichikawa, K.; J. Chromatogr. B 2005, 815, 3-9.

5. D'Ambrosio, C.; Arena, S.; Talamo, F.; Ledda, L.; Renzone, G.; Ferrara, L.; Scaloni, A. J. Chromatogr. B 2005, 815, 157-168.

6. Capriotti, A. L.; Cavaliere, C.; Foglia, P.; Samperi, R.; Lagana, $A$. J. Chromatogr. A 2011, 1218, 8760-8776.

7. Kelleher, N. L. Anal. Chem. 2004, 76, 196A-203A.

8. Reid, G. E.; McLuckey, S. A. J. Mass Spectrom. 2002, 37, 663675.

9. McQueen, P.; Krokhin, O. Expert Rev. Proteomics 2012, 9, $125-$ 128.

10. Moradian, A.; Kalli, A.; Sweredoski, M. J.; Hess, S. Proteomics 2014, 14, 489-497.

11. Ahmed, F. E. J. Sep. Sci. 2009, 32, 771-798

12. Gedela, S.; Medicherla, N. R. Chromatographia 2007, 65, 511518.

13. Selvaraju, S.; El Rassi, Z. Electrophoresis 2012, 33, 74-88.

14. Tomáš, R.; Kleárník, K.; Foret, F. J. Sep. Sci. 2008, 31, 1964-1979.

15. Horvatovich, P.; Hoekman, B.; Govorukhina, N.; Bischoff, R. J. Sep. Sci. 2010, 33, 1421-1437.
16. Donato, P.; Cacciola, F.; Mondello, L.; Dugo, P. J. Chromatogr. A 2011, 1218, 8777-8790.

17. Rigobello-Masini M.; Penteado, J. C. P.; Masini, J. C. Anal. Bioanal. Chem. 2013, 405, 2107-2122.

18. Li, Y.; Lee, M. L. J. Sep. Sci. 2009, 32, 3369-3378.

19. Yue, G.; Luo, Q.; Zhang, J.; Wu, S.; Karger, B. L. Anal. Chem. 2007, 79, 938-946.

20. Luo, Q.; Yue, G.; Valaskovic, G. A.; Gu, Y.; Wu, S.; Karger, B. L. Anal. Chem. 2007, 79, 6174-6181.

21. Luo, Q.; Rejtar, T.; Wu, S.; Karger, B. L. J. Chromatogr. A 2009, $1216,1223-1231$

22. Thakur, D.; Rejtar, T.; Wang, D.; Bones, J.; Cha, S.; ClodfelderMiller, B.; Richardson, E.; Binns, S.; Dahiya, S.; Sgroi, D.; Karger, B. L. J. Chromatogr. A 2011, 1218, 8168-8174.

23. Wang, D.; Hincapie, M.; Rejtar, T.; Karger, B. L. Anal. Chem. 2011, 83, 2029-2037.

24. Rogeberg, M.; Wilson, S. R.; Greibrokk, T.; Lundanes, E. J. Chromatogr. A 2010, 1217, 2782-2786.

25. Huang, X.; Zhang, J.; Horvath, C. J. Chromatogr. A 1999, 858, 91-101.

26. Eeltink, S.; Svec, F.; Frechet, J. M. J. Electrophoresis 2006, 27, 4249-4256.

27. Kašička, V. Electrophoresis 2012, 33, 48-73.

28. Kašička, V. Electrophoresis 2010, 31, 122-146.

29. El Rassi, Z. Electrophoresis 2010, 31, 174-191.

30. Nilsson, C.; Birnbaum, S.; Nilsson, S. Electrophoresis 2011, 32, 1141-1147.

31. Sun, L.; Zhu, G.; Yan, X.; Champion, M. M.; Dovichi, N. J. Proteomics 2014, 14, 622-628.

32. Karenga, S.; El Rassi, Z. J. Sep. Sci. 2008, 31, 2677-2685.

33. Rocco1, A.; Aturki, Z.; D’Orazio, G.; Fanali, S.; Šolínová, V.; Hlaváček, J.; Kašička, V. Electrophoresis 2007, 28, 1689-1695.

34. Yang, Y.; Boysen, R. I.; Matyska, M. T.; Pesek, J. J.; Hearn, M. T. W. Anal. Chem. 2007, 79, 4942-4949.

35. Zaidi, S. A.; Cheong, W. J. J. Chromatogr. A 2009, 1216, 29472952.

36. Zaidi, S. A.; Cheong, W. J. Electrophoresis 2009, 30, 1603-1607.

37. Zaidi, S. A.; Han, K. M.; Hwang, D. G.; Cheong, W. J. Electrophoresis 2010, 31, 1019-1028.

38. Zaidi, S. A.; Lee, S. M.; Cheong, W. J. J. Chromatogr. A 2011, $1218,1291-1299$.

39. Cheong, W. J.; Yang, S. H.; Ali, F. J. Sep. Sci. 2013, 36, 609-628. 